\section{Desafios do Estado brasileiro diante da pandemia de COVID-19: o caso da paradiplomacia maranhense}

\author{
Challenges for the Brazilian State from the \\ COVID-19 pandemic: the case of paradiplomacy \\ in the state of Maranhão
}

\author{
Desafíos del Estado brasileño frente a la \\ pandemia por la COVID-19: el caso de \\ la paradiplomacia marañense
}

Alexandre Andrade Alvarenga 1 Erika Maria Sampaio Rocha 2 Jonathan Filippon 3 Maria Angélica Carvalho Andrade 4

\section{Resumo}

À medida que a pandemia de COVID-19 se espalhou pelo mundo em 2020, populações, autoridades e instituições locais e globais de governança em saúde foram atingidas de maneira distinta. A chamada Diplomacia em Saúde Global e a "paradiplomacia" tornaram-se instrumentos e arenas de relevância diante dos desafios trazidos pela pandemia, sobretudo para atores não estatais ou subnacionais. Este Ensaio analisa o caso do Estado do Maranhão, Brasil, no contexto da pandemia, que, por meio de uma "operação de guerra", comprou no mercado internacional mais de cem respiradores à revelia do Governo Federal, em um momento de acirrada competição internacional por materiais e equipamentos médicos. O Ensaio investiga os principais aspectos, contextos, razões, fatores, atores e ações que contextualizam a operação realizada pelo Estado do Maranhão, como uma atividade paradiplomática e de Diplomacia em Saúde Global de um ente subnacional no Brasil. Analisamos os conceitos citados à luz da literatura sobre o tema e estudamos a atuação do Maranhão a partir do cruzamento de dados de documentos, pronunciamentos e notícias. Concluímos que o caso maranhense ilustra a capacidade de entes locais responderem às emergências de cunho global, principalmente em contextos de ineficácia ou ausência do executivo federal, legitimando ações independentes que visem à proteção da vida.

Pandemias; COVID-19; Saúde Global; Diplomacia em Saúde; Capacidade de Liderança e Governança

\author{
Correspondência \\ E. M. S. Rocha \\ Universidade Federal do Sul da Bahia. \\ Pça. Joana Angélica 250, Teixeiras de Freitas, BA \\ 45988-058, Brasil. \\ emsampaiorocha@gmal.com \\ 1 Universidade Federal do Rio de Janeiro, Rio de Janeiro, Brasil. \\ 2 Universidade Federal do Sul da Bahia, Teixeira de Freitas, \\ Brasil. \\ 3 Queen Mary University of London, London, U.K. \\ 4 Universidade Federal do Espirito Santo, Vitória, Brasil.
}




\section{Introdução}

A guerra por equipamentos médicos é um fenômeno de grande repercussão nacional e mundial no contexto da pandemia de COVID-19. A compra de respiradores pelo Estado do Maranhão, Brasil, por meio de uma rota comercial "alternativa", é bastante reveladora da "guerra sem quartel" entre as nações por equipamentos médico-hospitalares e escancara o acirramento de uma competição econômica e diplomática. Além disso, expõe um elemento geopolítico desconcertante no contexto diplomático internacional, que é a ausência de liderança do governo brasileiro, com a consequente emergência de novos atores de instâncias subnacionais no cenário internacional 1,2.

Devido ao risco de colapso do sistema de saúde de um dos estados mais pobres do país, o governo do Maranhão resolveu agir. A "operação de guerra" maranhense foi montada após três tentativas frustradas do governo estadual de comprar respiradores de uso em cuidados hospitalares intensivos. A logística utilizada articulou a compra direta de respiradores da China, a partir de recursos doados por empresas locais, em uma iniciativa organizada pela Secretaria de Indústria e Comércio (SEINC) do Governo do Estado. Foram realizadas três operações comerciais com a China, que envolveram a compra de mais de 255 respiradores pulmonares e 200 mil máscaras de proteção ${ }^{3}$. A estratégia foi traçada depois de os respiradores serem reservados pelas vias burocráticas "normais" por três vezes e atravessados pelos Estados Unidos, pela Alemanha e pelo próprio governo brasileiro 4. Assim, o governo do Maranhão, alterou a rota de compra e trouxe a mercadoria pela Etiópia. Ao desembarcar em São Paulo, Brasil, a carga foi diretamente para o Maranhão, onde passou pelos trâmites da Receita Federal 4,5,6.

No entanto, apesar do sucesso inicial da operação, o governo maranhense foi acusado pelo Governo Federal de ultrapassar as suas competências constitucionais, requisitando a posse dos aparelhos. A situação foi resolvida pelo Supremo Tribunal Federal, que determinou a devolução dos respiradores ao Maranhão, alegando ser essa uma questão emergencial 7,8.

Ressalta-se que a atuação internacional de governos subnacionais, denominada paradiplomacia, representa uma profunda mudança no campo de estudos da Análise de Política Externa (APE) e das Relações Internacionais 9 , principalmente em decorrência dos processos de globalização. O fenômeno da paradiplomacia subnacional é um processo geopolítico de extroversão de atores de forma autônoma em relação ao Governo Central nas Relações Internacionais 10, que praticam atos e acordos internacionais para obterem recursos e resolverem problemas específicos com rapidez e facilidade, sem a intervenção dos governos centrais.

Nesse sentido, a paradiplomacia aponta para mudanças na tradicional escala de observação internacional, uma vez que as Relações Internacionais saem do foco exclusivo dos Estados-Nação e passam também a ser desenvolvidas por uma pluralidade de outros atores não estatais ou subnacionais, como as paradiplomacias privada, governamental, municipal e estadual 11,12. Esses atores, por sua vez, passam a atuar internacionalmente de maneira mais orgânica e articulada, muitas vezes à revelia do próprio Estado, em nome de interesses privados, comerciais ou econômicos, ou ainda em defesa de diferentes causas políticas 13 .

Em paralelo, o campo de estudo da Diplomacia da Saúde Global também vem se destacando dentro das agendas internacionais e da política externa dos estados, sobretudo em um contexto marcado pela evolução do conceito de desenvolvimento sustentável e pelo recente cenário de pandemia global. De forma geral, pode-se entender a Diplomacia em Saúde Global como um tema/área de política externa e internacional dedicada às principais questões de saúde global, coletiva e pública, envolvendo também temas de comércio, segurança e desenvolvimento sustentável. Esse tipo de diplomacia se manifesta, sobretudo, pela cooperação inter e intragovernamental de ministérios, agências, instituições, municipalidades e governos estaduais 13,14 .

No contexto da atual pandemia e à medida que ela se espalha pelo mundo, a atuação internacional do governo maranhense apresenta-se, então, como um disparador deste Ensaio. Por que um ente subnacional estaria empenhando esforços na busca da sua inserção internacional?

Este Ensaio propõe-se a analisar o caso de paradiplomacia do Estado do Maranhão na compra dos respiradores da China no contexto da pandemia de COVID-19. Embora as evidências a respeito dos desafios brasileiros para lidar com o novo coronavírus no campo da Saúde Global sejam ainda incipientes, a partir do caso maranhense, notícias divulgadas na mídia, notas oficiais do governo e 
relatórios de organizações internacionais apontam para três elementos considerados fundamentais para esta análise: o discurso negacionista da Presidência da República do Brasil, que vem boicotando o enfrentamento da pandemia; as tensões diplomáticas e os retrocessos comerciais com a China, o maior parceiro comercial do Brasil e exportador mundial de medicamentos, equipamentos e materiais médico-hospitalares; e o isolamento diplomático, as críticas e os ataques do Brasil ao multilateralismo e aos organismos internacionais de Governança Global da Saúde. Para iniciar este Ensaio, partimos da contextualização histórica do conceito e da experiência brasileira em paradiplomacia.

\section{Paradiplomacia: conceitos e experiência brasileira}

O conceito de "paradiplomacia" desenvolveu-se para caracterizar toda ação externa promovida por um ator não estatal ou subestatal que produz alguma influência ou resultado internacional. Essa abordagem desenvolveu-se, inicialmente, pelos trabalhos de Snyder e Rosnau, na década de 1960, que reforçaram a premissa de que atores e fatores domésticos, assim como os atores internacionais, são relevantes para a formulação e para o conteúdo da política externa 13 .

Na década de 1980, esse debate ganhou força na literatura norte-americana com os trabalhos de Duchacek e Soldatos, que cunharam o termo "paradiplomacia" para caracterizar a atuação internacional dos entes subnacionais fora da estrutura tradicional do Estado, fazendo referência ao termo parallel diplomacy. Assim, a paradiplomacia referia-se às relações e atividades políticas, econômicas e sociais que os atores subnacionais (regiões, províncias, estados federados, cidades, comunidades urbanas) desenvolviam com outros governos nacionais, entes subnacionais, organizações internacionais e outros atores para fins políticos, comerciais, industriais, financeiros, técnicos, culturais ou geopolíticos. Essas atividades, por sua vez, podiam apoiar, complementar, corrigir, duplicar ou desafiar a diplomacia do estado nacional 15 .

A partir da década de 1990, surge o termo "pós-diplomacia" para caracterizar um processo que se manifesta além do estado nacional e de sua diplomacia tradicional. Formula-se também o conceito de "diplomacia de múltiplas camadas" (multilayered diplomacy), para se referir às interações entre as esferas centrais e regionais e aos temas que interessam a ambos no cenário internacional 15.

As atividades paradiplomáticas variam com o contexto político e constitucional de cada país, bem como com os diferentes motivos, interesses, ações, estratégias e meios. A ineficiência ou debilidade dos governos centrais para atender às demandas e necessidades políticas e econômicas impulsiona os atores subnacionais a se relacionarem com outros entes federados, governos centrais e instituições internacionais 11,15 .

Seguindo esse debate, a paradiplomacia passou a ser definida como o envolvimento de governos subnacionais nas Relações Internacionais, por meio de contatos formais e informais, permanentes ou provisórios, com entidades estrangeiras públicas ou privadas, objetivando promover resultados socioeconômicos, políticos ou de outra dimensão externa ao alcance de sua competência constitucional 15.

No Brasil, a associação da política externa ao estado nacional e ao ministério de relações exteriores (ou secretaria de negócios estrangeiros) remonta aos tempos de colonização portuguesa, passando pela independência, Império e República. Nesse processo, destaca-se a relativa autonomia, o profissionalismo e a tradição histórica da diplomacia brasileira, especialmente em fóruns multilaterais.

A partir da década de 1980, com a perda do monopólio do Ministério das Relações Exteriores na formulação da política externa brasileira, destaca-se o protagonismo de outros ministérios, como, por exemplo, o Ministério da Fazenda, nas negociações financeiras internacionais sobre a dívida externa do país. As ações interministeriais, por sua vez, passam a coordenar fóruns multilaterais e as conferências de desenvolvimento sustentável e saúde global. Ressalta-se, ainda, a crescente participação de organizações não governamentais e de entidades subnacionais 13 .

Mudanças estruturais externas e domésticas (fim da Guerra Fria, globalização, ascensão de novos atores não estatais, redemocratização, Constituição Federal de 1988), na década de 1990, favoreceram o protagonismo de atores antes negligenciados pelas estruturas de poder 9,12. Paralelamente, o debate acadêmico intensificou-se no país, classificando esse fenômeno como diplomacia federativa, com duas interpretações: uma "positiva", aditiva à diplomacia clássica, e outra "negativa", que o considerava um desvio da diplomacia 15. 
No âmbito jurídico/constitucional, não há um pronunciamento legal sobre a legitimidade das ações internacionais promovidas por entidades subnacionais. Segundo a Constituição Federal, compete à União manter Relações Internacionais, com algumas prerrogativas exclusivas, sem proibir os estados e municípios de promoverem relações com outros estados e de participar de organizações internacionais. Tramita no Congresso Nacional, desde 2005, uma proposta de emenda constitucional que estabelecerá maior autonomia e apoio aos estados e municípios para promover suas Relações Internacionais 10.

Os estados e municípios passaram a participar mais ativamente das relações exteriores, com os processos de integração regional de cooperação Sul-Sul, tendo a promoção econômica e a cooperação política e técnica 15 como as áreas de maior articulação.

No plano prático, atualmente, 22 estados federados (dentre os 26 e o Distrito Federal) e 366 municípios brasileiros possuem algum tipo de órgão que trata de Relações Internacionais 11,15. No Estado de São Paulo, por exemplo, governos e políticos locais vêm incentivando as municipalidades a buscar parcerias e investimentos externos. No Amapá, por sua vez, alguns políticos investiram no estreitamento de relações com o governo francês, em razão das relações fronteiriças com a Guiana Francesa, o que pode gerar também importantes ações e resultados em relação à política de preservação regional da Amazônia 11.

Dentre as iniciativas paradiplomáticas no Maranhão, no início do mandato, o governador Flávio Dino deflagrou aproximações com representantes políticos e empresários chineses em prol de investimentos nos setores de energia, siderurgia e tecnologia, o que representou fortalecimento de Relações Internacionais com o mercado chinês, além de prospectar investimentos com os países do BRICS (Brasil, Rússia, Índia, China e África do Sul) 16.

Flávio Dino recebeu, em 2017, o embaixador de Israel para discutir propostas de cooperação institucional e acadêmica, desenvolvimento agrícola e oportunidades para empresários locais e internacionais 17 . Nesse mesmo ano, o governador assinou um termo de cooperação técnica com a Organização Pan-Americana da Saúde (OPAS) e a Organização Mundial da Saúde (OMS) na área de atenção materno-infantil 18 .

Em 2019, o Maranhão liderou a criação do Consórcio do Nordeste, um bloco subnacional de cooperação política e socieoconômica, que passou a buscar investimentos e parcerias público-privadas (PPP) para projetos de infraestrutura e tecnologias, inclusive no âmbito internacional ${ }^{19}$. Os governadores e representantes dos estados da região participaram de missões comerciais internacionais a fim de apresentar o potencial econômico da região e negociar investimentos com empresários locais em diversas áreas 20.

Diante da pandemia de COVID-19, o governo do Estado do Maranhão protagonizou uma surpreendente operação paradiplomática, que chamou atenção dos meios de comunicação, da comunidade médica e acadêmica, sobretudo na área de Diplomacia em Saúde Global. No entanto, vale ainda destacar que essa operação seguiu um movimento já identificado desde anos 1980 no Brasil e já realizado pelo estado do Maranhão em outros momentos. A partir dos conceitos já apresentados, serão analisados os três elementos considerados fundamentais, iniciando-se pelo discurso negacionista da Presidência da República do Brasil.

\section{O discurso negacionista da "aliança do avestruz"}

O primeiro elemento diz respeito ao discurso negacionista do governo brasileiro, às ações defendidas por ele e suas implicações, dificultando o enfrentamento do novo coronavírus. A minimização do impacto do vírus, o questionamento das regras de distanciamento social, defendendo a denominada "imunidade de rebanho", contrastam com o posicionamento de países que obtiveram resultados eficazes no controle da pandemia 21.

O caso do Maranhão revela as dificuldades para o enfrentamento do COVID-19 e os constrangimentos de ministros, governadores e outras instâncias gestoras diante da posição negacionista do presidente da República em relação às abundantes evidências científicas 21 , do cerceamento de iniciativas do Ministério da Saúde, do Sistema Único de Saúde (SUS) e dos governos estaduais e municipais na busca por medidas de socorro para a população brasileira 22 . 
No que se refere ao discurso negacionista, o presidente brasileiro alinha-se a um pequeno grupo de líderes mundiais (Bielorrússia, Turcomenistão e Nicarágua) que ignoram a seriedade e a gravidade da pandemia e, por isso, receberam o apelido "Aliança de Avestruz", por sua comparação com a ave que esconde a cabeça no solo, quando em situação de perigo 23. A "Aliança de Avestruz", exposta em número recente do Financial Times, questionou a postura do Presidente Jair Bolsonaro no cenário global diante da pandemia, indicando o retrocesso nas Relações Internacionais e na Diplomacia em Saúde 24.

Em junho de 2020, dentre os mais de 22,2 milhões de casos confirmados e de 780 mil mortes no mundo (OMS. WHO Coronavirus Disease [COVID-19] Dashboard. https://covid19.who.int/, acessado em 20/Jun/2020), registram-se oficialmente no Brasil, o país com maior número de casos confirmados da América do Sul e o segundo no mundo, mais de 3,5 milhões de pessoas infectadas pela COVID-19, com mais de 112 mil mortos e com uma letalidade de 3,2\% (Ministério da Saúde. Coronavírus Brasil. https://covid.saude.gov.br, acessado em 20/Jun/2020).

Segundo a OMS, a grande subnotificação de casos da doença e de mortos, devido principalmente à baixa testagem diagnóstica da população, juntamente com uma curva ascendente de novas mortes, já posicionaria o Brasil como o mais novo epicentro mundial da pandemia pelo novo coronavírus 25 .

Diante das proporções da COVID-19 e das condições de vida da população brasileira, a análise recente do Colégio Imperial de Londres (Reino Unido) recomenda ações com maior urgência. A instituição, que é referência em pandemias no Reino Unido, mostrou uma estimativa para o Brasil de duplicação do número de mortes a cada cinco dias, sendo a taxa de transmissão (R0) de 2.81 a mais alta dentre os 48 países estudados 26 .

As necessidades impostas pela pandemia tornam-se ainda mais urgentes em um país que tem a precarização do trabalho como um dado estrutural, cujo processo tem se acentuado com o avanço da agenda neoliberal nos últimos trinta anos 27 , acarretando uma classe trabalhadora cada vez mais destituída de direitos e garantias 28.

Entretanto, questionado sobre o rápido aumento de casos brasileiros, o presidente da República respondeu: “E daí? Lamento, quer que eu faça o quêe?", em uma postura de irresponsabilidade e desrespeito sem precedentes, sendo retratado como uma séria ameaça à saúde da humanidade 26 .

Mesmo denunciado no Tribunal Internacional de Haia por crime contra a humanidade, devido à sua negligência com as políticas de isolamento, Presidente Jair Bolsonaro segue à margem do debate mundial, difundindo o uso de um remédio sem eficácia comprovada - a hidroxicloroquina - para tratar infecções por COVID-19 e tecendo ataques injustificáveis às recomendações da OMS 2,29.

Nesse sentido, a postura da Presidência da República do Brasil constitui hoje uma das maiores dificuldades para o enfrentamento do novo coronavírus, diante de suas posições negacionistas, distorcendo fatos na ampla mídia, confundindo a população de maneira irresponsável e criando entraves às iniciativas de governadores e prefeitos 2,26 .

Destaca-se que, com o advento da pandemia, o governo do Maranhão reconheceu a gravidade da situação e elaborou um plano de contingência, com uma série de decretos que estabeleciam ações de prevenção e de isolamento social e que reafirmavam o estado de pandemia da OMS 30. No entanto, no que diz respeito à compra de materiais e equipamentos médicos, o governo do estado encontrou dificuldades de acesso e aquisição, devido à exacerbada competição mundial por equipamentos médicos e pelo descaso e desorganização do Governo Federal em relação à pandemia.

Vale ainda ressaltar que o Consórcio do Nordeste também criou um comitê científico para auxiliar os gestores da região na tomada de decisões para o enfrentamento da pandemia. Essa foi uma iniciativa que envolve cientistas do Brasil, da Itália, da Alemanha, da China e de outros países para discutir soluções na tentativa de mitigar a disseminação de casos da COVID-19 31.

\section{Tensões diplomáticas, retrocesso comercial e "pirataria moderna"}

O segundo elemento diz respeito às dificuldades criadas a partir de tensões diplomáticas do Brasil com a China e da passividade do Governo Federal e do Ministério das Relações Exteriores na área comercial, em um contexto de disputas globais por acesso aos suprimentos e equipamentos médico-hospitalares. Esse cenário de pandemia, de paralisação econômica e de escassez de alguns produtos tem lançado alguns países a uma "caça ao tesouro global", em que ações de "pirataria moderna" para 
aquisição de suprimentos e equipamentos médicos passaram a fazer parte das transações comerciais globais, evidenciando a falta de solidariedade internacional e a falta de liderança e de governança no campo da saúde global 32.

Nesse contexto, alguns governos atravessaram, desviaram e confiscaram cargas de equipamentos destinadas a outros países, como o caso dos Estados Unidos, da Alemanha e da França, que desviaram cargas de equipamentos médicos da China que iriam para Itália, República Checa e Brasil. Diante desse fenômeno, o governo brasileiro demonstrou-se passivo em relação aos Estados Unidos (que desviou os equipamentos brasileiros) e envolveu-se em tensões diplomáticas com a China (maior exportador de equipamentos) por motivos ideológicos, promovidas, sobretudo, pelo presidente da República e pelo ministro das relações exteriores, o que custou ao Brasil certa posição de prioridade em relação às exportações chinesas, além de cancelamentos e atrasos. Essa situação impactou e comprometeu profundamente as estratégias do SUS e de governos estaduais, que se viram forçados a agir por meio de canais extraoficiais, como o caso do Governo do Maranhão ${ }^{6}$.

Também é preciso destacar a dependência estrutural do complexo econômico industrial brasileiro na área de saúde, que não consegue suprir toda demanda doméstica por insumos básicos, tampouco por equipamentos tecnológicos, condicionando o país a recorrer ao comércio internacional. Entende-se como "complexo econômico e industrial da saúde" todos os atores e atividades voltadas para produção, pesquisa, inovação e tecnologia em saúde, pensados em conjunto, que visam a atender às demandas da saúde coletiva, a promover o desenvolvimento econômico nacional e a superar dificuldades estruturais externas 33 .

Para alguns autores, existe uma situação de assimetria global que exclui estruturalmente países, regiões e populações do acesso à saúde, evidenciando uma divisão internacional do trabalho, em que alguns países se tornam meros consumidores de tecnologia, ao passo que outros definem o padrão tecnológico global, exercendo um domínio geopolítico que se desdobra para as políticas sociais e universais de saúde 33 .

Historicamente, o déficit do Brasil nessa área foi suprido pela capacidade tecnológica e de inovação da União Europeia e dos Estados Unidos e, mais recentemente, pela Índia e China, que promoveram avanços em seus respectivos complexos industriais e tecnológicos nas últimas décadas. Ao contrário, o Brasil cortou investimentos em saúde, educação, pesquisa e desenvolvimento por meio da Emenda Constitucional no 95, também conhecida como a Emenda Constitucional do Teto dos Gastos Públicos ${ }^{34}$.

É importante também destacar que, além dos impactos sociais e do caráter estruturante das políticas e práticas da inovação tecnológica na saúde, o desenvolvimento de medicamentos, vacinas, recursos para diagnóstico, equipamentos ou inovações é também um campo de disputas políticas e econômicas do qual participam países produtores e dependentes de tecnologias, organizações internacionais, empresas privadas, institutos públicos e organizações não governamentais nacionais e internacionais, entre outros atores relevantes. Nesse sentido, é preciso também reconhecer que a saúde é fortemente influenciada por instituições, políticas (domésticas, externas e internacionais) e temas como comércio, propriedade intelectual, trabalho ou meio ambiente, entre outros 35 .

Diante de sua dependência estrutural, o Brasil é forçado a buscar suprimentos e equipamentos por meio do comércio internacional, muitas vezes sujeito a questões e interesses econômicos e geopolíticos, o que demanda uma visão mais realista e pragmática da realidade internacional para garantir seus objetivos. Contudo, em nível internacional, além da desconcertante ausência de liderança do governo nos principais fóruns e iniciativas internacionais sobre o combate à pandemia e sobre acesso universal à vacina e aos equipamentos necessários, o Brasil tem atuado de forma pouco pragmática também em relação a sua política de comércio exterior, criando tensões com a China, investindo pouco ou de forma errada (cloroquina) no seu complexo econômico industrial da saúde e posicionando-se de forma passiva em relação aos recentes fenômenos de pirataria moderna.

Essas situações expõem a dependência externa do Brasil em relação a medicamentos, equipamentos e materiais médico-hospitalares, além de evidenciar a carência e as dificuldades de um complexo industrial e tecnológico da saúde que não consegue atender nem à demanda doméstica. Isso cria uma dependência em relação à China e abre espaço para a atuação de entes federativos, como o caso do governo do Maranhão. Com relação ao comércio internacional brasileiro, é importante ressaltar que, segundo o Ministério da Economia, o fluxo de comércio (exportações e importações) do Brasil com 
a China é de cerca de USD 100 bilhões, com um superávit para o Brasil de USD 30 bilhões. Nesse cenário, os chineses respondem por $27,8 \%$ das exportações e $20 \%$ das importações 36 .

Várias e recentes insinuações de políticos brasileiros criaram constrangimentos e estremecimentos nas relações com o governo chinês 37,38 , considerado o maior parceiro no mercado externo do Brasil e maior produtor de equipamentos de proteção individual (EPIs) e ventiladores pulmonares, intensificando a dificuldade de se obter equipamentos, tanto para a proteção dos profissionais de saúde, quanto para o suporte de vida dos pacientes graves da COVID-19 38.

Com esses incidentes diplomáticos, as posições do presidente Bolsonaro na gestão das ações diante da pandemia deixam os governadores sem apoio e cerceados nas estratégias de assistência às populações, exigindo dos governos subnacionais, inclusive, a redefinição de seus papéis internacionais. Nessa nova lógica, os governadores têm desconsiderado os posicionamentos presidenciais e tomado para si a responsabilidade da condução das medidas de enfrentamento da COVID-19, incluindo a definição dos rumos da política externa do país, uma vez que a implementação das decisões tende a ser cada vez mais descentralizada, assim como seus efeitos na promoção do bem-estar social.

Os EPIs e os ventiladores pulmonares são mercadorias globalmente escassas e não há disponibilidade facilitada nem quantidade suficiente desses itens. Salienta-se que a disponibilidade dos ventiladores pulmonares para pacientes graves pelo novo coronavírus pode ser determinante entre o óbito ou a sobrevida. Na luta pela hegemonia econômica e pelo padrão tecnológico global de alta relevância para as políticas nacionais de saúde, o fato de o país ser independente do mercado mundial ou ter acesso comercial garante a segurança dos cidadãos 32.

Com o avanço do coronavírus, o mundo tomou conhecimento de que a produção de remédios, equipamentos e materiais médico-hospitalares se concentra em poucos países e, à medida que os estoques diminuem, os governos relutam em permitir que equipamentos deixem seus países, ou os equipamentos são oferecidos a preços exorbitantes. Apesar do alerta da OMS sobre a acumulação e a escassez de equipamentos de proteção, a enorme especulação financeira e a disputa global sobre esses produtos deixam vulneráveis os profissionais de áreas essenciais no enfrentamento da COVID-19 32.

No contexto da pandemia, "assegurar o acesso das populações dos países em desenvolvimento a produtos de saúde a preços não abusivos deveria ser prioridade máxima para a saúde global” 35 (p. S8) e para a Organização Mundial do Comércio (OMC). Em meio a uma corrida mundial por milhares de equipamentos fabricados pela China, a situação maranhense também expõe essa disputa global e os comportamentos criminosos de pirataria moderna, que intercepta e toma para si mercadorias e produtos que são dos outros 2 .

Nessa conjuntura, vários governos europeus alertaram sobre a dificuldade de obter equipamentos de proteção para os profissionais de saúde, como a França e a Alemanha, que acusaram os Estados Unidos de tentar sequestrar seus pedidos de máscaras de proteção e luvas. De modo geral, o desvio de suprimentos cruciais tem sido feito pela interceptação da entrega dos pedidos e pela tentativa de pagar aos fornecedores chineses três ou quatro vezes mais do que o preço acordado 19.

Destaca-se ainda que houve interrupção de toda a exportação de máscaras produzidas nos Estados Unidos, a partir da invocação do governo americano à Lei de Produção de Defesa, de 1950, que concede ao governo amplos poderes para direcionar a sua produção industrial durante emergências 32.

Faz-se importante ainda ressaltar que, após a operação comercial e logística internacional do Maranhão, Flávio Dino ressaltou os princípios constitucionais que regem as Relações Internacionais no Brasil e a ruptura promovida pelo Governo Federal na política externa brasileira. Para o governador, o reconhecido posicionamento de independência do Brasil em sua política externa deu lugar a uma espécie de sombreamento nunca antes visto. Com isso, nosso país segue diretrizes unilaterais de um país, no caso dos Estados Unidos, em alinhamento quase automático. O pior é que há evidências reiteradas de tratar-se de uma relação platônica, de mão única, com escassos resultados e graves contradições 39 . 


\section{Isolamento diplomático, críticas ao multilateralismo e fragilidades na governança da saúde global}

O terceiro elemento enfatiza os entraves nas relações entre o Brasil e os organismos internacionais de Governança Global da Saúde, como a OMS. A controversa retenção, por parte dos Estados Unidos e da Alemanha, dos respiradores adquiridos por brasileiros aponta para um processo de acirramento da competição em escala mundial e de agravamento da crise de governança global da OMS, reiterando a existência de assimetrias tecnológicas globais que excluem estruturalmente países, regiões e populações do acesso à saúde, fortalecendo a existência de desigualdades nos padrões nacionais de desenvolvimento, que se somam às iniquidades sociais 2,33 .

A OMS declarou, em 30 de janeiro de 2020, que o surto da doença causada pelo novo coronavírus constitui uma Emergência de Saúde Pública de Importância Internacional (ESPII), considerada o mais alto nível de alerta da Organização, conforme previsto no Regulamento Sanitário Internacional. Essa é a sexta vez na história que uma ESPII é declarada, e esse tipo de declaração potencialmente requer uma resposta internacional coordenada e imediata, aprimorando-se a cooperação e a solidariedade global para interromper a propagação do vírus 40 .

Em 11 de março de 2020, a COVID-19 foi caracterizada pela OMS como uma pandemia, referindo-se à distribuição geográfica da doença, e não à sua gravidade. Essa designação reconhece que, no momento, existem surtos do novo coronavírus em vários países e regiões do mundo. Destaca-se que esses dois marcos do novo coronavírus aproximaram ainda mais os temas de saúde global, tanto dos debates geopolíticos, quanto dos debates cotidianos da população 40 .

É importante ressaltar que a expressão "saúde global" deve levar em consideração "as necessidades de saúde da população de todo o planeta, acima dos interesses de nações em particular" 41 (p. 625), valorizando a crescente importância de atores para além de agências e organizações governamentais e intergovernamentais. Salienta-se que a expressão "saúde global" emergiu como parte de um processo histórico e político, no contexto de uma ordem mundial neoliberal. Nesse contexto, a OMS é compreendida como uma agência intergovernamental que desempenha funções internacionais com o objetivo de melhorar a saúde global 41 .

Entretanto, nessa nova área da saúde global, são reformuladas "antigas disputas ideológicas, geopolíticas e metodológicas que operam na esfera internacional, formando um campo que pode tanto oferecer oportunidades reais para a busca da equidade como encobrir interesses e agendas particulares dos mais diversos teores" 2.

Originalmente considerada a maior autoridade técnica e porta-voz da saúde no mundo, diretora e coordenadora da atuação internacional no domínio da saúde, a OMS tinha como uma de suas funções dar uma espécie de enquadramento político e técnico em matéria de saúde pública aos Estados. Entretanto, a OMS "viu seu papel, antes dominante, ser desafiado, e começou a reposicionar-se no âmbito de um conjunto de alianças de poder em transformação" 41 (p. 641).

Esse papel da OMS na governança da saúde global tem recebido muitas críticas, o que vem desencadeando um processo de reformas da organização de alcance limitado em face da complexidade atual da saúde para as políticas sociais nacionais e globais 35. A OMS vem enfrentando dificuldades desde 1990, destacando-se as seguintes: a redução do seu protagonismo diante da concorrência com outros organismos internacionais e entidades privadas, inclusive as filantrópicas; a escassez e a natureza do seu financiamento; os conflitos de interesse dos especialistas; as dificuldades de comunicação; e os problemas de governança interna 42 . Nesse contexto, organizações não governamentais, fundações privadas, outras agências das Nações Unidas e grandes empresas transnacionais vêm progressivamente ocupando espaços no direcionamento das políticas globais 35 .

Recentemente, a pandemia de COVID-19 tem dado à crise da OMS uma nova dimensão, o que tem dificultado cada vez mais a sua capacidade de orquestrar respostas aos desafios da saúde global, a exemplo do fato de a maior autoridade sanitária mundial ter orçamento modesto e não desfrutar da devida importância política, o que a faz dependente de financiadores, cujas prioridades nem sempre estão alinhadas às necessidades das populações 43 .

A complexidade internacional das últimas décadas, aliada a uma crise econômica global e à atual conjuntura da pandemia, acirra tensões entre países e organizações internacionais, em especial Estados Unidos e China, bem como a OMS. Nesse contexto, destaca-se a suspensão financeira dos Estados Unidos, fazendo com que a OMS perdesse em torno de $15 \%$ do seu financiamento total. Uma das 
justificativas do presidente americano para a medida adotada em meio ao pico de coronavírus nos Estados Unidos era que a OMS beneficiava a China na resposta à pandemia, e não cobrava do país asiático a responsabilidade pela origem e disseminação do COVID-19, que, segundo presidente estadunidense Donald Trump, seria "um vírus chinês" originado em um laboratório da cidade de Wuhan, na China 44,45.

As autoridades alemãs expressaram dúvidas com relação à explicação dada pelos líderes americanos, e os chineses classificaram de "insanos" os julgamentos contra o país, acusando o governo Trump de xenofobia, e afirmando que o presidente americano queria se livrar da responsabilidade sobre o impacto do coronavírus em seu país. A OMS denunciou as declarações como "especulativas" e sem fundamento, uma vez que os americanos não apresentaram provas que sustentassem essa teoria. A China reiterou seu apoio à OMS e se opôs à tentativa dos Estados Unidos de politizar a pandemia 44,45,46. A falta de interesse de Donald Trump em liderar a resposta à crise sanitária e o protagonismo da China apontavam para uma inversão na relação de poder entre os países 2.

Nesse contexto, inicialmente, o presidente americano ameaçou retirar os Estados Unidos da OMS e suspender indefinidamente as contribuições financeiras de seu país à entidade, criticando o que considera uma dependência da OMS em relação à China e sugerindo a desvinculação de Pequim 47. Posteriormente, Trump afirmou que está encerrando relações com a OMS e que vai realocar financiamento, antes destinado ao órgão, para outras iniciativas 48.

É importante destacar que, atualmente, os Estados Unidos são o maior financiador da OMS, com contribuições anuais em torno de 400 a 500 milhões de dólares. Além disso, é o país mais afetado do mundo pela pandemia de COVID-19, com mais de 5,4 milhões de casos (https://covid19.who.int/, acessado em 20/Jun/2020) 47.

Além disso, a OMS também vem sendo acusada por Taiwan (China) de negligência, por não ter questionado a versão inicial chinesa sobre a COVID-19, quando Pequim sustentava que o vírus não era transmitido de um ser humano para outro 36.

Nessa grave conjuntura, o caso do Maranhão também aponta para uma significativa mudança do papel de liderança internacional do Estado brasileiro, particularmente nos fóruns internacionais relacionados à saúde. Nesses fóruns, o Brasil passou a adotar uma posição de isolamento ou conflito, sendo muitas vezes considerado um "pária internacional", devido ao desconcerto entre o governo brasileiro e os principais países que estão discutindo o tema e tomando ações contra a pandemia 2 .

O Brasil desempenhou, em vários momentos da história contemporânea, papéis relevantes, tanto de liderança quanto de crítica em relação a diversos temas de saúde pública e global, como no caso da criação e do desenvolvimento da OMS e no combate a doenças tropicais. Também ampliou o conceito de Saúde Pública ao criar o campo da Saúde Coletiva, construído na luta pela redemocratização na década de 1970. É signatário da Declaração da OMS de Alma Ata, de 1979, e de Astana, de 2019, sobre atenção primária à saúde (APS). Destacou-se internacionalmente pelo Sistema Único de Saúde (SUS), integral, público, gratuito e universal, e pelo seu modelo de APS, a Estratégia Saúde da Família (ESF), bem como pelo modelo de financiamento que a colocou na posição de ordenadora de toda a Rede de Atenção à Saúde (RAS) 49,50.

No cenário internacional, o Brasil teve um papel relevante na evolução do campo emergente da Saúde Global, exercendo uma postura de crítica e de conciliação nos fóruns internacionais de saúde e promovendo debates, consensos e soluções multilaterais e fundamentadas na Cooperação Sul-Sul, quando passou a ser reconhecido como importante articulador de interesses entre os países desenvolvidos e em desenvolvimento. Foi fundamental nas discussões da OMC sobre saúde e propriedade intelectual, o que resultou na Declaração de Doha sobre Saúde, e no Acordo sobre Aspectos dos Direitos de Propriedade Intelectual Relacionados ao Comércio (TRIPS). No âmbito pan-americano, sempre foi atuante, mediou decisões embasadas pelos grupos e câmaras técnicas, promovendo suporte aos demais países latinos e exercendo pressão sobre empresas farmacêuticas e sobre o complexo industrial da saúde, no sentido da melhoria do acesso e da qualificação do cuidado às populações. No âmbito sul-americano, liderou a criação do Conselho de Saúde da União de Nações Sul-Americanas (UNASUL) e do Instituto Sul Americano de Governança em Saúde (ISAGS), com sede no Rio de Janeiro, que deveria coordenar as políticas nacionais de saúde e promover cooperação entre os países. No Mercado Comum do Sul (MERCOSUL), liderou a criação de um banco de preços de medicamentos e coordenou a compra coletiva de medicamentos dos países do bloco 51 . 
Na política para combate ao tabagismo, o Brasil presidiu a comissão para a Convenção-Quadro para o Controle do Tabaco da OMS (CQTC/OMS), além de ter uma das legislações mais avançadas 52. Nos programas de abordagem do HIV/aids, o Brasil consolidou-se como referência internacional nas políticas públicas de enfrentamento à epidemia de HIV/aids, com marcada atuação na quebra de patentes e na distribuição de medicamentos no decorrer dos anos 1990 e 2000 53,54,55.

A tradição de articulador e de liderança crítica na Diplomacia em Saúde, no entanto, vem sendo abandonada, culminando com o encerramento da participação do Brasil na Cooperação Sul-Sul, a partir de 2019 56. Seguiram-se diversas posições de retrocesso, tanto na política internacional, como também nas ações na política interna, acirrando o desmonte do SUS e privilegiando o setor privado, agravando as desigualdades e a vulnerabilidade social da maior parte da população brasileira.

Nesse contexto da pandemia, o governador do Maranhão também ressaltou que o Brasil perdeu parte de seu "poder brando" no mundo, de sua capacidade de influenciar outras nações e de estabelecer relações de confiança. Além disso, lamentou que a diplomacia brasileira perdeu seu profissionalismo, secundarizou as agendas de desenvolvimento, como educação, saúde, direitos humanos e meio ambiente, e desvalorizou o multilateralismo, aliando-se a um belicismo contra as instâncias supranacionais, supostamente priorizando acordos bilaterais. Destacou também as dificuldades de relacionamento do Brasil no Mercosul, os impasses com a União Europeia e o esvaziamento do BRICS, promovido pelo Governo Federal. Lembrou também que a realidade econômica do Brasil precisa de parceiros comerciais externos e que é preciso repensar a política diplomática do país para proteger empresas e empregos. Ao final, criticou as batalhas puramente fraseológicas e os delírios ideológicos do governo, reforçando a necessidade de maior independência, responsabilidade e entendimento sobre o interesse nacional 39.

\section{Considerações finais}

O Governo do Estado do Maranhão protagonizou uma surpreendente operação comercial e logística internacional para a compra de respiradores pulmonares, organizando uma "operação logística de guerra" em meio à disputa comercial e geopolítica global entre as principais potências internacionais. Essa operação pode ser caracterizada como um exemplo concreto de "paradiplomacia" e de "diplomacia em saúde global”. No entanto, há que se destacar que existiram fatores, atores, ações e estratégias que tornaram essa empreitada possível e que fazem parte de um fenômeno recorrente e crescente no Brasil, desde o final do século XX.

Vale destacar que se tratou de uma ação externa promovida por um ente subnacional, que já praticava atividades paradiplomáticas, mas que se viu diante de dificuldades que impediam a prevenção e o combate adequado à pandemia de COVID-19. Para superar essas adversidades, buscou parcerias locais e internacionais, além de mostrar-se alinhado às orientações e políticas da OMS e da OPAS, demonstrando também uma atuação na área da Diplomacia da Saúde Global. Os achados deste estudo ressaltam a importância, relevância e necessidade do protagonismo de entes públicos locais, os quais, não apenas em situações de emergência, mas, especialmente nestas, podem e devem posicionar-se na contextualização internacional quando necessário, explorando parcerias internacionais que visem à proteção da população local, desde que amparadas por reconhecido conhecimento científico.

No que diz respeito às dificuldades e fragilidades conjunturais, ressaltam-se, além da própria pandemia e de suas consequências econômicas, a crise do multilateralismo e da "governança global em saúde", a "pirataria moderna", o discurso negacionista do Governo Federal do ponto de vista científico, o alinhamento ideológico da política externa brasileira, as tensões diplomáticas com a China e com a OMS e a própria desorganização e incapacidade do governo federal para lidar com a situação de forma pragmática, embasada em evidências científicas. Nesse sentido, o governador do Maranhão intensificou a prática da paradiplomacia diante do vácuo deixado pelas fragilidades e pela falta de liderança do governo brasileiro no âmbito doméstico, internacional e global.

Fazendo um contraponto às dificuldades, destacam-se as práticas paradiplomáticas promovidas pelo governo do Maranhão que ajudaram a ampliar o diálogo político, o comércio, a cooperação técnica e as demais relações sociais, aprofundadas, sobretudo, a partir do primeiro mandato do governador Flávio Dino, em 2014, em especial com China, Israel, Itália, OMS e OPAS. Além disso, ressalta-se 
sua liderança direta no processo de criação do Consórcio do Nordeste, um contraponto concreto às políticas econômicas e à política externa do governo federal.

Dentre as estratégias, ressaltam-se as missões comerciais, os diálogos diplomáticos, as iniciativas de coordenação subnacional e, principalmente, a "operação de guerra" montada para trazer os respiradores e outros materiais e equipamentos médico-hospitalares e para escapar da "pirataria moderna", causada principalmente por Estados Unidos e Alemanha, e da possibilidade de apreensão pela Receita Federal. Por fim, destacam-se as manifestações abertas de sua opinião sobre a política externa brasileira atual e suas críticas ao Governo Federal.

É importante ainda destacar que as aberturas subnacionais ao sistema internacional explicam-se como parte de uma política deliberada em busca de oportunidades, vantagens e benefícios políticos e socioeconômicos que podem ou não estar alinhados às posições do governo central, desenvolvendo com este uma relação de cooperação ou de conflito, uma vez que o crescente envolvimento de governos subnacionais em política externa também pode ser entendido como indício de um significativo declínio da confiança depositada nos governos centrais. Isso não significa que governos centrais devam apenas contar com o protagonismo das autoridades locais. Tanto a saúde pública quanto outros aspectos do bem-estar social devem ser o resultado do equilíbrio de responsabilidades financeiras e de gestão entre ambos, governos locais e nacionais, dentro do arranjo de governança nacional, no caso brasileiro, baseados no pacto federativo entre o ente federal, estados e municípios.

No contexto nacional, a pandemia explicitou o caráter de um governo comprometido com interesses neoliberais do capitalismo rentista, abstendo-se da inerente responsabilidade social diante de um cenário de crônica desigualdade. $\mathrm{O}$ caso do Maranhão revelou as dificuldades, as soluções e a emergência de novos conflitos com o Governo Federal. Como resultado dessas atividades, o governador está sendo acusado de quebra do pacto federativo e responde a um processo criminal movido pela Receita Federal. Enquanto isso, os crimes contra a humanidade, os crimes de pirataria e o descaso com a saúde pública nacional seguem impunes.

\section{Colaboradores}

Todos os autores contribuíram com a concepção do projeto, análise, discussão, redação do artigo e aprovação da sua versão final a ser publicada.

\section{Informações adicionais}

ORCID: Alexandre Andrade Alvarenga (00000001-6762-9282); Erika Maria Sampaio Rocha (0000-0003-4347-0531); Jonathan Filippon (00000003-3907-1992); Maria Angélica Carvalho Andrade (0000-0002-3690-6416). 


\section{Referências}

1. Lucena E, Lucena R. Prognóstico é ruim e vai piorar, diz Fiori. Tutaméia 2020; 10 abr. https://tutameia.jor.br/prognostico-e-ruim-evai-piorar-diz-fiori/.

2. Ventura D. Geopolítica da pandemia: "A verdade é que hoje o Brasil é um pária internacional”. Pública 2020; 27 abr. https://apublica. org/2020/04/geopolitica-da-pandemia-a-ver dade-e-que-hoje-o-brasil-e-um-paria-inter nacional-diz-especialista-em-saudeglobal/?fbclid=IwAR27NHU34_QppKNgkUIf1Jbg2QuEqMpE6roPIX_eqN3e87GOWUVfB7mRfoI.

3. Secretaria de Saúde do Estado. Mais de cem respiradores chegam ao Maranhão para pacientes com coronavírus. https://www.sau de.ma.gov.br/destaques/mais-de-cem-respi radores-chegam-ao-maranhao-para-pa cientes-com-coronavirus/ (acessado em 20/ Ago/2020).

4. Rede Brasil Atual. Receita vai processar Flávio Dino por 'operação de guerra' que garantiu respiradores ao Maranhão. Rede Brasil Atual 2020; 20 abr. https://www.redebrasilatual. com.br/politica/2020/04/receita-vai-proces sar-flavio-dino-por-operacao-de-guerra-quegarantiu-respiradores-ao-maranhao/.

5. Após ser acusado de compra ilegal, Flávio Dino posta vídeo com respirador e "uma vida sendo salva”. Jornal do Commercio 2020; 20 abr. https://jc.ne10.uol.com.br/politica/2020/04/ 5606680-apos-ser-acusado-de-compra-ile gal-flavio-dino-posta-video-com-respirador -e--uma-vida-sendo-salva.html.

6. Mota E. Receita Federal diz que Maranhão trouxe respiradores ilegalmente da China; governo reage. Congresso em Foco 2020; 20 abr. https://congressoemfoco.uol.com.br/saude/ receita-federal-diz-que-maranhao-trouxe-res piradores-ilegalmente-da-china-governo-rea ge/.

7. Secretaria de Saúde do Estado. Mais 104 respiradores chegam ao Maranhão para reforçar combate ao COVID-19. https://www.saude. ma.gov.br/destaques/mais-104-respirado res-chegam-ao-maranhao-para-reforcar-com bate-a-covid-19/ (acessado em 20/Ago/2020).

8. Secretaria de Saúde do Estado. Em meio a disputa global. Maranhão recebe mais de 250 respiradores em menos de um mês. https://www. saude.ma.gov.br/destaques/em-meio-a-dispu ta-global-maranhao-recebe-mais-de-250-res piradores-em-menos-de-um-mes/ (acessado em 20/Ago/2020).

9. Ribeiro MCM. Globalização e novos atores: a paradiplomacia das cidades brasileiras. Salvador: EdUFBA; 2009.

10. Moreira FA, Senhoras EM, Vitte CCS. Geopolítica da paradiplomacia subnacional: um estudo sobre a extroversão internacional dos municípios da rede de Mercocidades. In: XII Encuentro de Geógrafos de América Latina; 2009. https://works.bepress.com/eloi/122/ (acessado em 20/Ago/2020).
11. Vigevani T, Wanderley LE, Cintra R. Ação Internacional das cidades no contexto da globalização. Cadernos Cedec 2006; (80). http:// www.cedec.org.br/files_pdf/CAD80.pdf.

12. Milani CMS, Ribeiro MCM. Paradiplomacia y proyección internacional de las ciudades brasileñas: la elaboración del concepto de "gestión internacional local". Geopolítica(s): Revista de Estudios Sobre Espacio y Poder 2010; 1:23-40.

13. Milani C, Pinheiro L. Política externa brasileira: os desafios de sua caracterização como política pública. Contexto Internacional 2013; 35:11-41.

14. Buss PM, Ferreira JR. Diplomacia da saúde e cooperação Sul-Sul: as experiências da Unasul saúde e do Plano Estratégico de Cooperação em Saúde da Comunidade de Países de Língua Portuguesa (CPLP). RECIIS 2010; 1:106-18.

15. Gonçalvez FCNI, Oliveira PC. A política externa (sub) nacional: um estudo da paradiplomacia do Estado do Rio de Janeiro e de sua relação com o governo federal. Conjuntura Global 2017; 6:94115.

16. Estado do Maranhão. Flavio Dino apresenta atributos econômicos do Maranhão para empresários chineses. https://www3.ma.gov.br/ flavio-dino-apresenta-atributos-economicosdo-maranhao-para-empresarios-chineses/ (acessado em 20/Ago/2020).

17. Estado do Maranhão. Governo estreita relações de cooperação internacional com Israel. https://www3.ma.gov.br/maranhao-estreitarelacoes-de-cooperacao-internacional-comisrael/ (acessado em 20/Ago/2020).

18. Estado do Maranhão. Governo celebra cooperação com organizações internacionais e fortalece rede materno-infantil no estado. https://www3.ma.gov.br/governo-celebracooperacao-com-organizacoes-internacionais -e-fortalece-rede-materno-infantil-no-esta do/ (acessado em 20/Ago/2020).

19. Froés R, Cardoso R, Barbosa A. Governadores do Nordeste assinam no Maranhão documento que cria consórcio entre estados. G1 2019; 14 mar. https://g1.globo.com/ma/maranhao/ noticia/2019/03/14/governadores-do-nor deste-assinam-no-maranhao-documento-quecria-consorcio-entre-estados.ghtml (acessado em 20/Ago/2020).

20. Estado do Maranhão. Dezenas de empresários italianos conhecem oportunidades de negócio no Nordeste. https://www3.ma.gov. $\mathrm{br} /$ dezenas-de-empresarios-italianos-conhe cem-oportunidades-de-negocio-no-nordeste/ (acessado em 20/Ago/2020).

21. Campos GWS. O pesadelo macabro da Covid-19 no Brasil: entre negacionismos e desvarios. Trab Educ Saúde 2020; 18:e00279111.

22. Conselho Nacional de Saúde. Carta aberta: CNS em defesa da vida, da democracia e do SUS. https://conselho.saude.gov.br/ulti mas-noticias-cns/1140-cartaaberta-do-con selho-nacional-de-saude-em-defesa-da-vi da-da-democracia-e-do-sus (acessado em 20/ Jun/2020). 
23. 'Aliança do Avestruz': FT destaca grupo de Bolsonaro e outros líderes que 'se recusam a levar coronavírus a sério’ BBC Brasil 2020; 17 abr. https://www.bbc.com/portuguese/inter nacional-52328505.

24. The 'Ostrich Alliance': the leaders denying the coronavirus threat. Financial Times 2020; 26 abr. https://www.ft.com/content/974dc9d277c1-4381-adcd-2f755333a36b.

25. Barrucho L. BBC Brasil. Brasil: o novo epicentro da pandemia de coronavírus? BBC Brasil 2020; 20 mai. https://www.bbc.com/portu guese/brasil-52732620.

26. The Lancet. COVID-19 in Brazil: "So what?" Lancet 2020; 395:1461.

27. Pochmann M. O emprego no desenvolvimento da nação. São Paulo: Boitempo Editorial; 2008.

28. Antunes R. O privilégio da servidão: o novo proletariado de serviços na era digital. São Paulo: Boitempo Editorial; 2018.

29. Eisenhammer S, Stargardter G. Bolsonaro colocou generais para combater coronavírus, e Brasil está perdendo a batalha. UOL Economia 2020; 26 mai. https://economia.uol.com. br/noticias/reuters/2020/05/26/especial-bol sonaro-colocou-generais-para-combatercoronavirus-e-brasil-esta-perdendo-a-bata lha.amp.htm?_twitter_impression=true.

30. Estado do Maranhão. Decreto no 35.660, de 16 de março de 2020. Dispõe sobre os procedimentos e regras para fins de prevenção da transmissão da COVID-19, institui o Comitê Estadual de Prevenção e Combate à COVID-19 e dá outras providências. Diário Oficial do Estado 2020; 16 mar.

31. Santos A. Governadores do Nordeste criam comitê científico contra coronavírus. UOL 2020; 30 mar. https://noticias.uol.com.br/po litica/ultimas-noticias/2020/03/30/governa dores-do-nordeste-criam-comite-cientificocontra-coronavirus.htm.

32. Lister T, Shukla S, Bobille F. Pandemia de coronavírus desencadeia disputa global por máscaras de proteção. CNN Brasil 2020; 5 abr. https://www.cnnbrasil.com.br/internacio nal/2020/04/05/pandemia-de-coronavirusdesencadeia-disputa-global-por-mascaras-deprotecao.

33. Gadelha CAG, Nascimento MAC, Braga PSC, Cesario BB. Transformações e assimetrias tecnológicas globais: estratégia de desenvolvimento e desafios estruturais para o Sistema Único de Saúde. Ciênc Saúde Colet 2018; 23:2119-32.

34. Brasil. Emenda Constitucional no 95, de 15 de dezembro de 2016. Altera o Ato das Disposições Constitucionais Transitórias, para instituir o Novo Regime Fiscal, e dá outras providências. Diário Oficial da União 2016; 15 dez.

35. Buss PM, Chamas C, Faid M, Morel C. Desenvolvimento, saúde e política internacional: a dimensão da pesquisa \& inovação. Cad Saúde Pública 2016; 32 Suppl 2:e00046815.
36. Aranha C. Clima esquenta na OMS com acusação de negligência feita por Taiwan. Exame 2020; 14 abr. https://exame.abril.com.br/ mundo/clima-esquenta-na-oms-com-acusa cao-de-negligencia-feita-por-taiwan/.

37. 'China é aquele cara que você sabe que tem que aguentar', diz ministro Paulo Guedes. G1 2020; 22 mai. https://g1.globo.com/politica/ noticia/2020/05/22/china-e-aquele-cara-quevoce-sabe-que-tem-que-aguentar-diz-minis tro-paulo-guedes.ghtml.

38. Freitas C. Maia: Não entendo como o governo desqualifica a China neste momento. Valor Econômico 2020; 19 abr. https://valor.globo. $\mathrm{com} /$ politica/noticia/2020/04/07/maia-naoentendo-como-o-governo-desqualifica-a-china-neste-momento.ghtml.

39. Estado do Maranhão. Artigo do Governador: o Brasil e o mundo. https://www3.ma.gov.br/ artigo-do-governador-o-brasil-e-o-mundo/ (acessado em 20/Ago/2020).

40. Organização Pan-Americana da Saúde. Folha informativa - COVID-19 (doença causada pelo novo coronavírus). https://www.paho. org/bra/index.php?option=com_content\& view $=$ article $\& \mathrm{id}=6101$ : covid $19 \&$ Itemid $=875$ (acessado em 17/Jul/2020).

41. Brown TM, Cueto M, Fee E. A transição de saúde pública 'internacional' para 'global' e a Organização Mundial da Saúde. Hist Ciênc Saúde-Manguinhos 2006; 13:623-647.

42. Ventura D, Perez FA. Crise e reforma da organização mundial da saúde. Lua Nova 2014; (92):45-77.

43. Santos JV. "Sem democracia, sem ciência, sem educação, sem renda, sem políticas sociais e sem direitos, seguiremos muito doentes". Entrevista especial com Deisy Ventura. http:// www.ihu.unisinos.br/159-noticias/entrevis tas/597307-sem-democracia-sem-cienciasem-educacao-sem-renda-sem-politicas-so ciais-e-sem-direitos-seguiremos-muito-doen tes-entrevista-especial-com-deisy-ventura (acessado em 25/Mai/2020).

44. Fiorillo M. Corte de financiamento da OMS pelos Estados Unidos pode ter consequências globais. Jornal da USP 2020; 17 abr. https:// jornal.usp.br/radio-usp/corte-de-financia mento-da-oms-pelos-estados-unidos-podeter-consequencias-globais/.

45. Roubicek M. Como China e EUA acirram tensões na pandemia. NEXO 2020; 18 mai. https://www.nexojornal.com.br/expres so/2020/05/18/Como-China-e-EUA-acir ram-tens\%C3\%B5es-na-pandemia.

46. Alemanha questiona explicações dos EUA sobre origem do coronavírus. Correio do Povo 2020 ; 5 mai. https://www.correiodopovo.com.br/not\%C3\%Adcias/mundo/alema nha-questiona-explica\%C3\%A7\%C3\%B5esdos-eua-sobre-origem-do-coronav\%C $3 \%$ Adrus-1.419666. 
47. Trump ameaça retirar Estados Unidos da OMS PODER 360 2020; 19 mai. https://www.po der360.com.br/coronavirus/trump-ameacaretirar-eua-da-oms-dw/.

48. Trump rompe com OMS e acusa China de ser responsável por 'sofrimento no mundo'. G1 2020; 29 mai. https://g1.globo.com/mundo/ noticia/2020/05/29/trump-diz-que-esta-en cerrando-relacoes-com-a-oms-e-faz-criticas -a-china.ghtml.

49. Macinko J, Mendonça CS. Estratégia Saúde da Família, um forte modelo de Atenção Primária à Saúde que traz resultados. Saúde Debate 2018; 42 spe 1:18-37.

50. Russo LX, Scott A, Sivey P, Dias J. Primary care physicians and infant mortality: evidence from Brazil. PLoS One 2019; 14:e0217614.

51. Buss PM, Tobar S. Diplomacia em Saúde e Saúde Global: perspectivas latino-americanas. Rio de Janeiro: Editora Fiocruz; 2017.

52. Silva ST, Martins MC, Faria FR, Cotta RMM. Combate ao Tabagismo no Brasil: a importância estratégica das ações governamentais. Ciênc Saúde Coletiva 2014; 19:539-52.
53. Cueto M, Lopes G. AIDS, antiretrovirals, Brazil and the international politics of global health, 1996-2008. Soc Hist Med 2019; hkz044.

54. Kitchenman S. Inúmeros desafios do passado proporcionam aos portadores de HIV o largo acesso aos antirretrovirais no presente. Physis (Rio J.) 2012; 22:1243-8.

55. Barreto ML, Teixeira MG, Bastos FI, Ximenes RAA, Barata RB, Rodrigues L. Successes and failures in the control of infectious diseases in Brazil: social and environmental context, policies, interventions, and research needs. Lancet 2011; 377:1877-89.

56. Buss PM. A pandemia e a cooperação internacional em saúde. Abrasco 2020; 30 mar. https://www.abrasco.org.br/site/noticias/ opiniao/artigo-a-pandemia-e-a-cooperacaointernacional-em-saude/46217/. 


\section{Abstract}

As the COVID-19 pandemic has spread worldwide in 2020, populations, authorities, and local and global health governance institutions have been affected differently. Global Health Diplomacy and "paradiplomacy" have become relevant instruments and arenas for the challenges raised by the pandemic, especially for non-State or subnational actors. This Essay analyzes the case of the Maranhão State, Brazil, during the pandemic, which used a "wartime operation" to purchase more than a hundred mechanical ventilators on the international market, over the Federal Government's head, at a moment of fierce international competition for medical supplies and equipment. The Essay examines the principal aspects, contexts, reasons, factors, actors, and actions that contextualize the operation conducted by the state of Maranhão as an activity in paradiplomacy and Global Health Diplomacy by a subnational government in Brazil. We analyzed these concepts in light of the literature on the topic and studied the action by Maranhão based on cross-analysis of data from documents, statements, and news coverage. We conclude that the case of Maranhão illustrates the capacity of subnational bodies to respond to global emergencies, mainly in contexts of inefficacy or absence of the Federal executive, legitimizing independent action aimed at saving lives.

Pandemics; COVID-19; Global Health; Health Diplomacy; Leadership and Governance Capacity

\section{Resumen}

A medida que la pandemia de COVID-19 se extendió por el mundo en 2020, poblaciones, autoridades e instituciones locales y globales de gobernanza en salud se vieron afectadas de manera distinta. La llamada Diplomacia en Salud Global y la "paradiplomacia" se convirtieron en instrumentos y campos de relevancia ante los desafíos presentados por la pandemia, sobre todo para actores no estatales o entes subnacionales. Este Ensayo analiza el caso del Estado de Maranhão, Brasil, en el contexto de la pandemia, el cual mediante una "operación de guerra", compró en el mercado internacional más de cien respiradores, aun a pesar del Gobierno Federal, en un momento de acérrima competición internacional por materiales $y$ equipamientos médicos. El Ensayo investiga los principales aspectos, contextos, razones, factores, actores y acciones que contextualizan la operación realizada por el Estado de Maranhão como una actividad paradiplomática y de Diplomacia en Salud Global de un ente subnacional en Brasil. Analizamos los conceptos citados a la luz de la literatura sobre el tema y estudiamos la actuación de Maranhão, a partir del cruce de datos de documentos, pronunciamientos y noticias. Concluimos que el caso marañense ilustra la capacidad de entes locales en responder a las emergencias de cuño global, principalmente en contextos de ineficacia o ausencia del ejecutivo federal, legitimando acciones independientes que visen la protección a la vida.

Pandemia; COVID-19; Salud Global; Diplomacia en la Salud; Capacidad de Liderazgo y

Gobernanza
Recebido em 06/Jun/2020

Versão final reapresentada em 21/Ago/2020

Aprovado em 31/Ago/2020 